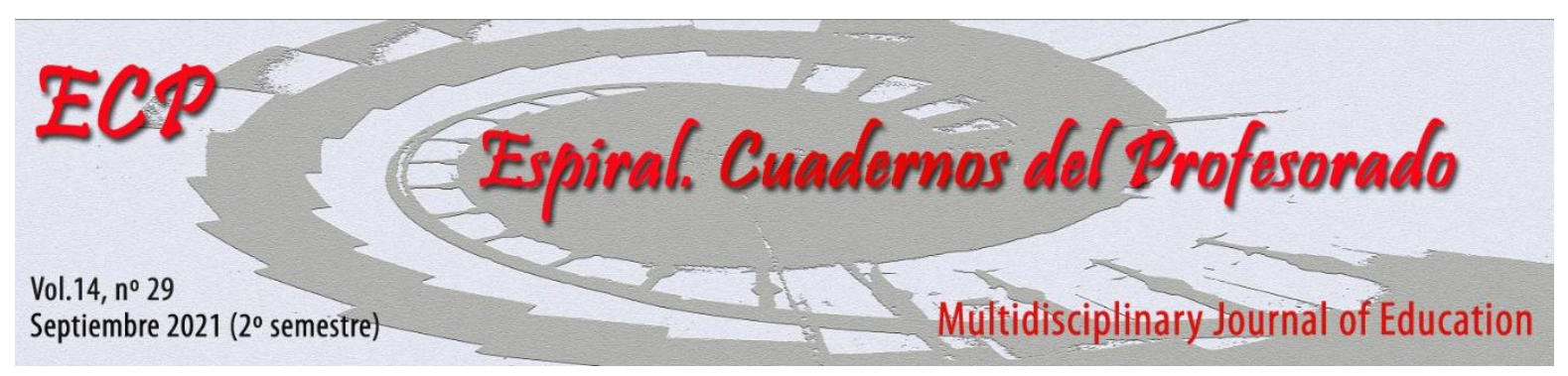

\title{
Aproximación etnolingüística a las teleclases universitarias en la primera cuarentena por COVID-19
}

\section{Ethnolinguistic approach to university online classes in thefirst quarantine by COVID- 19}

\author{
Antonio Daniel Fuentes González \\ Universidad de Almería, España
}

\section{Resumen}

Las medidas contra la nueva enfermedad COVID-19 invocaron un desafío importante para la enseñanza universitaria, pues en dos días de marzo de 2020 se tuvo que disponer una teledocencia para continuar en remoto. Atendiendo esa franja temporal, han surgido algunos trabajos, cuyas conclusiones suelen oscilar a) entre la focalización del déficit cibercompetencial del profesorado y b) el sentimiento de logro ante la emergencia. Este trabajo baraja el presupuesto teórico de que los dispositivos electrónicos y las aplicaciones que les dan sentido son correa de transmisión de la filosofía neoliberal, que todo convierte en mercancía, también la educación y su transfiguración en plataformización didáctica. A partir de la observación participante y desde la guía del modelo etnolingüístico SPEAKING, se abrirá una aproximación exploratoria sobre los principales aspectos comunicativos concitados durante la rigurosa cuarentena de la primavera de 2020, al tiempo que, más allá de unas medidas excepcionales, desentrañará los principales hitos propositivos interpelados para construir una competencia digital crítica, más cercana a los participantes de la actuación didáctica y menos centrada en el dispositivo y sus servidumbres aparentemente voluntarias.

Palabras clave: COVID-19; etnografía del habla; SPEAKING; observación participante; competencia digital crítica.

\begin{abstract}
The measures taken against the disease COVID-19 disease invoked an important challenge for university education, as in only two days back in March 2020 the education had to be arranged to continue remotely. In this time frame, a number of studies have emerged, the conclusions of which tend to oscillate between a) the focus on teachers' e-skills deficit and b) the feeling of achievement in the light of emergency. This work considers the theoretical assumption that electronic devices and the applications that give them meaning are the transmission chain of the neoliberal philosophy, which turns everything into merchandise, including education and its transfiguration into didactic platform. From the participant observation and the guide of the ethnolinguistic model SPEAKING, an exploratory approach will be opened on the main communicative aspects raised during the strict quarantine in spring 2020, while, beyond some exceptional measures, will unravel the main proposed milestones in order to build a critical digital competence, closer to the participants of the didactic action and less focused on the device and its seemingly voluntary servitudes.
\end{abstract}

Keywords: COVID-19; ethnography of speech; SPEAKING; participant observation; critical digital competence

Fecha de recepción: 26/01/2021

Fecha de aceptación: 04/03/2021

Correspondencia: Antonio Daniel Fuentes González, Universidad de Almería, España Email: dfuentes@ual.es 


\section{Introducción: Hacia la digitalización de la educación superior}

El gobierno de España decretó el 14 de marzo de 2020 el estado de alarma para controlar la propagación de una nueva enfermedad infectorrespiratoria, la COVID- $19^{1}$. Durante el fin de semana del 14 y 15 de febrero de 2020, las universidades dispusieron aceleradamente una serie de herramientas para que la docencia continuara desde los domicilios de estudiantes y profesorado. Básicamente, se proporcionaron aplicaciones complementarias en modo de videoconferencias desde las aulas virtuales. En la Universidad de Almería, como en cualquier otra universidad, ese proceso ha sido elogiado intrainstitucionalmente, en especial por la velocidad con que fue llevado a cabo.

Este trabajo propone analizar dicho proceso mediante la observación participante que dé cuenta de otros ángulos cotidianos. Durante la escritura de este artículo, el horizonte parece indicar que tendremos todavía el segundo cuatrimestre del curso 2020-2021 en modo de "no presencialidad", término incorporado al discurso académico durante esta pandemia. Se han ofrecido cursos de formación en didáctica digital o - más modestamente - en el uso de aplicaciones que procuran remedar una enseñanza presencial, con resultados, como se verá, controvertidos, que parecen dirigirnos, no obstante, a culminar la misión de éxito. También, durante el curso 2020-2021 se han implantado procedimientos mixtos, donde el profesorado, provisto de mascarilla y obediente a una escrupulosa y disciplinada normativa sanitaria, debía atender simultáneamente al grupo de estudiantes en el aula y al grupo no presencial que escuchaba ante sus ordenadores.

Para clarificar todo ello, se propone esta etnografía, con esa observación participante, particularmente durante el periodo de confinamiento de marzo a junio de 2020. Así, se intentará desentrañar el conjunto de aspectos linguocomunicativos en ese renovado teleayuntamiento de maestros y estudiantes con el ánimo de estudiar. Me valdré del modelo de análisis SPEAKING, ideado por Hymes (1974) desde los presupuestos teórico-metodológicos de la etnografía del habla (Guber, 2001; Golluscio, 2002), que considero también válido para la etnografía de cuño digital (Hine, 2000/2004; Ruiz \& Aguirre, 2015).

Con ello, se persigue una aproximación reflexiva y crítica a la digitalización, ante la que nos dirigimos aceleradamente, poniendo sobre el tapete y cuestionando los objetivos mercantilistas que necesitan sobremanera acentuar el déficit de los participantes para ensalzar jolgoriosamente las ventajas de esa enseñanza virtual en forma de cibermercancías.

\section{Una cala bibliográfica: La experiencia docente durante la pandemia de marzo de 2020}

En fechas recientes, la Comisión Europea (2017) publicaba el Marco Común de Competencia Digital Docente, muy influido por el Marco Común Europeo de Referencias para las Lenguas: Aprendizaje, enseñanza, evaluación (Consejo de Europa, 20001/2002). Esta nueva competencia está siendo examinada — sobrevenida pero también decididamente - a la vista de las necesidades didácticas en el confinamiento sociosanitario. Así, el periodo de estado alarma, prácticamente mundializado, ha espoleado una toma de conciencia multifacética ${ }^{2}$ desde puntos de observación donde se examina dicha competencia. De ese modo, Gabarrón (2020), en relación con el profesorado de lenguas extranjeras y su vinculación con las competencias comunicativa y sociolingüística, clarifica las diferencias entre una verdadera digitalización didáctica creativa y un mero hacer por hacer que exporte didácticas antiguas a nuevos formatos electrónicos.

La Universidad de Navarra ha coordinado un volumen titulado Aprendizajes de la enseñanza universitaria en tiempos de la COVID-19, destacando su "gran determinación [ya que], profesores y estudiantes continuaron sus clases en remoto gracias a la tecnología disponible y a una responsabilidad ejemplar" (Fernández-Gubieda, 2020, p. 9). Conviene tener en cuenta que se trata de un ejercicio de memoria institucional, de "no olvidar las lecciones de unos meses muy intensos, en los que casi cada día era preciso hacer frente a un nuevo desafío, resolver inquietudes, y marcar el rumbo con unas

\footnotetext{
${ }^{1} C f$. https://www.lamoncloa.gob.es/consejodeministros/resumenes/Paginas/2020/14032020_alarma.aspx

${ }^{2} C f$. cómo el buscador bibliográfico Google académico ha incorporado en un lugar prominente buscadores específicos dedicados al rastreo de la bibliografía sobre la enfermedad.
} 
prioridades previamente establecidas" (p. 9), porque "la innovación surge en entornos convulsos y perturbadores" p. 14), exigentes con

la pasión del profesor, el compromiso del alumno y la relación personal entre ellos. Esa es la química que desata la energía que se lleva por delante todos los obstáculos. Debemos avanzar juntos con realismo, flexibilidad y empatía. No hay sitio para el "sálvese quien pueda". Es hora de optimizar el aprendizaje de nuestros alumnos, desbloquear el talento de nuestros profesores y reinventar la universidad onlife (p. 14).

Como en tantos centros educativos, en los primeros momentos de choque, "[1]as clases magistrales se reducen en tiempo y espacio [sustituidas en parte] por un seguimiento al alumno [planteado como monográfico de autoayuda para] reconstruir la comunidad universitaria [que] no es un espacio físico (p. 15)", reconstruible desde la comunicación emocional. Así, "[1]os alumnos necesitan motivación basada en la escucha, aspiraciones y diálogos", de manera que la tiza no sea lo más importante, pero sin que los consejos tecnológicos nos abrumen, pues "[1]a tecnología está al servicio de la docencia. La buena pedagogía requiere: comunicación regular, efectiva y compasiva con los estudiantes (p. 15)."

De otro lado, Lovón y Cisneros (2020) estudian en una universidad peruana las repercusiones de las clases virtuales en los estudiantes universitarios, detectando cambios drásticos en los hábitos de vida de los participantes, pues hay no pocos casos de trastornos mentales por la implantación de una modalidad didáctica virtual. Sus resultados muestran que la principal consecuencia a) para el grupo estudiantil dotado de suficientes medios electrónicos es el estrés por sobrecarga académica; y, b) para el segundo, con escasos recursos tecnológicos, aparte del estrés, la frustración y la deserción universitaria.

En un entorno trinacional (Ecuador, España e Italia), Tejedor et al. (2020) han señalado que la mayoría de estudiantes ha percibido negativamente en este periodo pandémico la enseñanza en remoto, debido, fundamentalmente, al incremento de la carga lectiva, empeorando, asimismo, la valoración del profesorado, al tiempo que este ha echado de menos algunas competencias digitales básicas en los estudiantes. En ese sentido, se ha comprobado con frecuencia que muy buena parte del profesorado ha volcado bastantes más archivos sobre sus asignaturas, pero sin dar verdaderamente las clases, dispuestos en la mayor parte de las ocasiones a resolver dudas. Posiblemente, lo que nos ha costado más esfuerzo y sinsabores es el intento de dar una clase solvente y fluida. De ese modo, pareciera cobrar pleno sentido el hecho de que "el docente tiene que ser capaz de innovar, reflexionar y transformar sus propuestas didácticas para responder a las demandas sociales que vive el mundo en medio de una crisis sanitaria, a la vez que se alcancen los objetivos curriculares propuestos al inicio del curso" (p. 13), dando rienda suelta a ese nuevo Leviatán llamado digitalización, ahora sobrevenida, en la que por razones de fuerza mayor se ha acabado de implantar el último de los usos universitarios de internet:

1) presencia institucional en los nuevos espacios de comunicación social, 2) gestión a través de la red de cuestiones administrativas, 3) utilización de los recursos telemáticos con fines de investigación, 4) acceso virtual a los fondos bibliográficos y 5) espacio para la docencia apoyada en redes de ordenadores, para fines educativos (Aguaded \& Díaz (2009: 19)”.

En esa misma línea, Tejedor et al. (2020) opinan que "[p]ara que la teleformación funcione, es fundamental conocer de antemano las creencias que los profesores tengan respecto al papel que las TIC puedan desempeñar en la enseñanza [...], puesto que la poca alfabetización digital del profesorado dificulta la utilización técnico-didáctica de las TIC (p. 3)" (nótese el símil lingüístico), más allá del uso amplio o restringido dado a los nuevos dispositivos. De ese modo, la formación discursiva de la digitalización actúa con toda su crudeza con la nueva enfermedad, dado que

[1]a COVID-19 ha evidenciado la urgente transformación que demandan los sistemas educativos tradicionales y la importancia de poseer una estrategia educativa virtual, así como un alumnado y un profesorado con habilidades y competencias para la enseñanza y el aprendizaje en el ciberespacio. La irrupción de este virus planetario ha dejado constancia de las exigencias de una pandemia a las instituciones educativas: flexibilidad, plataformas, 
metodologías y contenidos adaptados a unos intercambios formativos mediados por las pantallas (p. 14).”

Dentro de ese panorama, Tejedor et al. (2020: 7), según esos datos obtenidos en Ecuador, Italia y España, el abrupto proceso de la presencialidad a la virtualidad ha sido considerado negativamente por la mayoría del alumnado. Para el profesorado, las cifras se reparten casi de modo igualitario entre una opinión positiva y otra negativa, además de un buen porcentaje que contempla tal cambio indiferentemente, sin olvidar que "[1]a calidad de la comunicación en los cursos online es una de las variables más señaladas en la literatura como precedente de la satisfacción del alumnado (p. 12), en lo que se abundará en este trabajo, pues creo que el déficit está precisamente en la enseñanza no presencial, presentada acríticamente como una competencia que, en cambio, suele generar una actuación manifiestamente mejorable.

Desde su experiencia mexicana, Abreu (2020) dirige sus reflexiones hacia las "respuestas improvisadas, que van desde lo absurdo hasta lo ingenioso en los colegios y universidades que luchan por continuar enseñando, incluso cuando sus estudiantes se han visto reflejados como imágenes diminutas en los monitores de sus computadores", con la asombrosa sensación de que en la virtualización docente se "ha pasado al punto de no retorno" que

puede hacer que la educación universitaria sea más accesible, menos costosa, interactiva y centrada en el estudiante. Sin embargo, sería sumamente engañoso si se presenta como una solución simple y práctica, capaz de reemplazar de forma inmediata la enseñanza presencial durante un período significativo (p. 3)

Abreu pone el dedo en su llaga al considerar que

la simple "onlinificación" de conferencias presenciales no dará como resultado experiencias positivas para académicos o estudiantes [dejando claro que] el mejor aprendizaje en línea permite a los usuarios interactuar entre ellos y no solo sentarse y escuchar una conferencia en línea. También permite a los participantes interactuar con los maestros, tal como lo harían en un aula (p. 5)

En esa línea argumental, Abreu muestra mucho empeño en diferenciar el sentido puro de lo que sería el aprendizaje en línea, frente a sentidos espurios politizados, como si cualquier propuesta conceptual no implicase su propia política; aun así, esa politización del término, por inundación semántica de sentidos ${ }^{3}$, prefiere diferenciar ese aprendizaje en línea de lo que ahora puede llamarse enseñanza remota de emergencia. Todo ello implica el uso de soluciones de enseñanza totalmente remotas para la instrucción que de otro modo se impartirían presencialmente. Parece claro que - en este entorno de crisis - los docentes que buscan asistencia suelen tener diferentes niveles de fluidez digital, muy necesaria para configurar una sana confianza virtual (p. 12), confianza que está llamada a jugar un rol muy importante en este tiempo de coronavirus, no tanto para que se haga lo mismo que en el aula física, sino para planificar cuidadosamente, sin emergencia y sin pánico (p. 14). Freire (2009) ya sostenía que la educación se estaba viendo afectada de forma radical por la emergencia de la cultura digital, provocando la imperiosa necesidad de innovar; una vez más, el tótem de la innovación ${ }^{4}$. Vale decir ahora que la educación no parece afectar mucho a la digitalización. La línea de producción, entonces, es unidireccional: la digitalización debe afectar a la educación, y no tanto a la inversa. Dentro de esa hegemonía de lo digital, su propio discurso instaura, como se verá, nociones que no se producen en diálogo con las instancias educativas, lo que pondrá de manifiesto el objetivo idílico-competencial de

\footnotetext{
${ }^{3}$ Creo que debida al prestigio que ha tomado con los años todo lo referente a la ciberesfera.

${ }^{4}$ Que quizá habría de cuestionarse en un entorno en que una tecnología biopolítica tan antigua como la cuarentena sea reclamada como el instrumento más eficaz para combatir la expansión de la COVID-19. Reparando posiblemente en ello, los responsables políticos prefirieron divulgar los términos 'confinamiento', 'restricciones de la movilidad' (este último sin demasiado éxito, frente al más usado 'toque de queda'), etc., que, a pesar de sus connotaciones policiales y militares, parecían ser más innovadores frente al antiguo y medieval de 'cuarentena'. En cualquier caso, para una interesante aproximación a la discursividad epidémica, vid. Morant y Martín (2011).
} 
que el profesor se convierta en un orientador y los estudiantes en buscadores trepidantes de nuevas cosas, arrojando la clase magistral, por ejemplo, a la papelera de reciclaje.

En lo que concierne a la plataformización de la educación, Jiménez y Rendueles (2020a, p. 97) recuerdan la creciente centralidad de las empresas tecnológicas en el mundo actual, lo que de ninguna forma propicia una digitalización mitigadora de los efectos del proyecto neoliberal. Más bien, con el capitalismo digital se está fortaleciendo la precarización laboral, la concentración monopolista, la financiarización y la pérdida de soberanía sociopolítica en detrimento de los sistemas de seguridad y bienestar sociales, colapsados e incapaces después de décadas del llamado austericidio (p. 95). Creo que es un serio aviso. De momento, el profesorado universitario ha sufrido un claro incremento de sus tareas, sobre todo por la adaptación a las nuevas plataformas, y no digamos en primaria y secundaria, donde las promesas de contrataciones masivas de docentes se han quedado en mera declaración política. Basta mirar, por otro lado, los despidos masivos que la digitalización está suponiendo en el sector bancario, consecuencias que en nuestro entorno profesional ya advierten para ELE Bruzos (2017) o Adell, Castañeda y Quintero (2018), quienes, frente a la "ubersidad", proponen prácticas docentes más críticas, democráticas, abiertas y flexibles.

Para legitimar las opiniones irrefrenablemente positivas sobre la enseñanza virtual, Prado (2001) sentenciaba dicotómicamente que el perfil del

profesor competente tecnológicamente es más versátil que el del docente del contexto educativo tradicional; pues, frente al clásico profesor, poseedor de saberes conceptuales incuestionables, mero transmisor de conocimientos, emisor de mensajes unidireccionales carentes de interactividad, el profesor del contexto educativo tecnológico es el formador que interactúa en el aula, plantea problemas, cuestiona soluciones, coordina el trabajo en colaboración y prepara a un alumnado con capacidades comunicativas versátiles (p. 23)

Así las cosas, parece que lo antedigital es desechable, con una llamada de supervivencia a esos "nuevos tiempos", donde todo será mucho mejor, interpelando nuestra responsabilidad, para caminar hacia lo abierto, hacia lo múltiple, hacia lo comunicativo, hacia la sociedad de la información (pp. 2930), como si lo no digital fuese a fortiori cerrado, incomunicado, uniforme y propio de la sociedad de la desinformación.

\section{Marco teórico-metodológico}

A partir de lo que pueda plantear la bibliografía especializada cibereducativa, insistente en señalar un déficit digital, sobre todo en el profesorado, es preciso cuestionar los soportes conceptuales y perceptivos planteados desde dicho déficit. Codó, Patiño-Santos y Unamuno (2012) consideran que debe objetarse la concepción clásica sobre la agentividad en los procesos sociolingüísticos, para añadir nuevas formas de agencia individual que negocien y renegocien espacios de contestación de las estructuras de poder y las ideologías dominantes a través del uso de nuevos géneros y nuevos canales. Es decir, que los nuevos dispositivos digitales pueden servir para una cosa y para la contraria, también para digitalizar ecolingüísticamente, si se quiere. Los trabajos de perspectiva etnográfica suelen desmenuzar muchas categorías (Hine, 2000/2004, pp. 105-145), pues pueden ser arbitrarias, o muy interesadas (como la dicotomía nativo digital vs. inmigrante o, la más reciente, residente vs. visitante). Con ello, deben darse sentido a modos sociolingüísticos de configuración cotidiana de perspectiva etnográfica, imbricados, asimismo, en los procesos globales de este cibercapitalismo, tomado por algo absolutamente novedoso, aunque no lo sea tanto (Jiménez \& Rendueles, 2020). El análisis, consiguientemente, no debe limitarse a la descripción de un fenómeno, sino a entender sus causas, sus tensiones internas y las posibles formas de abordar sus contradicciones, muy vinculadas a una violencia simbólica con la que el poder hegemónico siempre evita planteamientos críticos, sin conciencia histórica y deshistorizando las relaciones grupales (Codó, et al., 2012, p. 18), que en esta coyuntura pasa por entronizar la ciberenseñanza demonizando la enseñanza presencial. 
En tiempos prepandémicos ${ }^{5}$ Alves y Meneses (2018) destacan la centralidad del lenguaje como elemento de la digitalización; de ese modo, es de esperar que se produzcan y que se asienten, o no, nuevos repertorios sociolingüísticos desde el punto de vista de una conectividad eficaz, más como una "atividade constitutiva, cujo lócus de realização é a interação verbal" (p. 80). Esto es, se necesita un planteamiento lingüístico que facilite la intercomprensión a través de la construcción de significados consensuados. Desde luego, todo ello no lo van a negar las empresas tecnológicas, raudas al tildar sus aplicaciones de intuitivas y sus softwares de amistosos. Parto de la hipótesis de que el mercantilismo (tecnológico ahora) convierte discursivamente lo impuesto en consensuado. Compruébese, por ejemplo, cómo el canal garante de la sonoridad, la conectividad en este caso, es un bien precario en muchos domicilios. Así es como, en la búsqueda de un conjunto sistematizado de palabras que otorguen sentido a la digitalización, Santaella (2004) señala que en ese proceso constructivo "emergem soluções cada vez mais criativas e dinámicas (p. 10)", soluciones y compromisos que podrían convertir el aula virtual en una red social densa y fuerte (Juan, 2017), creatividad que colisiona con el principio quien tiene nombra que penetra individualmente en forma de obediencia semántica.

Ese consenso desde la obediencia es una forma disciplinaria que podría llamarse cibersometimiento, muy afinado, imperceptible, sin control político, implantando el internetcentrismo como árbitro del conocimiento y la conectividad como su sistema circulatorio. Las videoconferencias, en concreto, parecen ese nuevo mecanismo de control social que es el alambre de espino (Razac, 2015), transmutado ahora semióticamente con la tecnología, pero del que no llegamos a ser del todo conscientes. Más ordenadores, menos ladrillos, dijo en mayo de 2009 el presidente del gobierno español J. L. Rodríguez Zapatero ${ }^{6}$. La frase fue celebrada; íbamos a acabar con las lacras españolas de la desigualdad y del paro, hasta que apareció la brecha digital, que es un cibermodo de exclusión que produce una universidad pública vaciable por falta de rentabilidad, que en realidad es la negativa a invertir en un derecho fundamental, tomado como un gasto eliminable.

Lo digital ha sacralizado el plazo y convertido el calendario en lo más importante, en una hiperdisciplina inasequible al error. Se sigue desenterrando el mito de Kronos, gran agente que impide pensar porque siempre pasan cosas; impide reflexionar para mejorar, porque siempre hay nuevos útiles, nuevas "revoluciones digitales" que demandan nuestra adquisición, buscando nuevos modos de articulación y de circulación de mensajes sin que apenas pueda hacerse una lectura pública, propiciando el presumir de propiedades ontológicas ancladas a un Tengo, luego existo. Se fomenta como nunca el baile de las identidades donde una sociofobia alimentada también digitalmente hace que lo excéntrico se centralice y que lo común se haga periférico en un nuevo panóptico que funciona de modo que la población digital vigilada esté contenta, inconsciente de los aparatos ideológicos que los ahorman a través de prótesis tecnológicas que sueldan la comodidad a la calidez comunicativa en una extraña sociabilidad sin relaciones de codependencia, sin compromiso social, solo digital (Rendueles, 2013).

Con todo lo anterior, contar etnográficamente la implantación fulminante de la no presencialidad de la docencia bordea el riesgo de mostrarnos como supervivientes de nuestro propio éxito (o fracaso). Normalmente, en el discurso cotidiano académico ello se asocia al subjetivismo, dejando el objetivismo para esos seres significantes, tablas y cifras, o cifras entabladas, que, dicho sea de paso, también son subjetivas. Conviene por ello recordar que, hace algún tiempo, Max Weber (1904) interrogaba la objetividad y asumía la rentabilidad metodológica de la vivencia (Izquierdo Collado, 1991: 25-38). El estudio de esas vivencias didáctico-pandémicas se basa en el cuaderno de notas, en la conversación, ahora sin cara a cara y, sobre todo en la observación participante (Vid. Guasch, 1997; Duranti 1997/2000).

\footnotetext{
${ }^{5}$ Véase cómo puede estar asentándose el término 'covidceno' entendido como una fase concreta del 'capitaloceno' en "Nietzsche o las pandemias del Covidceno", por ANTONI AGUILÓ, 15/01/2021. Disponible en https://blogs.publico.es/dominiopublico/35967/nietzsche-o-las-pandemias-del-covidceno/

6 Vid. "Rodríguez Zapatero: «Menos ladrillos y más ordenadores»", 12 mayo 2009. Disponible en https://www.computing.es/infraestructuras/noticias/1030703001801/rodriguez-zapatero-menos-ladrillos-masordenadores.1.html
}

Espiral. Cuadernos del Profesorado | ISSN 1988-7701 | 2021, 14(29), 5-17 
Como modelo de análisis, me valdré del SPEAKING (Hymes (1974). En este acrónimo cada una de las letras se corresponde con las iniciales de los ocho macro-componentes del evento comunicativo que podrían servir para guiar la enunciación e interpretación de los procesos comunicacionales. Esos componentes quedan así explayados:

$\begin{array}{ll}\text { Setting and Scene } & \text { Situación y escena } \\ \text { Participants } & \text { Participantes } \\ \text { Ends } & \text { Finalidades } \\ \text { Acts Secuens } & \text { Secuencia de actos } \\ \text { Key } & \text { Clave } \\ \text { Instrumentalities } & \text { Instrumentos } \\ \text { Norms } & \text { Normas } \\ \text { Genre } & \text { Género }\end{array}$

\section{SPEAKING para las videoconferencias}

Durante el periodo cuarentenario del estado de alarma sanitario, de febrero a junio de 2020, básicamente el 2. ${ }^{\circ}$ cuatrimestre del curso 2019-2020, impartí Historia de la Lingüística, y he dirigido varios TFM (Trabajo de Fin de Máster) del Máster de Profesorado en Educación Secundaria y TFG (Trabajo de Fin de Grado) de las titulaciones de Filología Hispánica y de Humanidades. Es relevante señalar que el periodo inicial del cuatrimestre, sin cuarentena, sirvió para conocer personalmente al alumnado de la antedicha Historia de la Lingüística. El alumnado de TFG y de TFM ya era conocido de los estudios de grado.

Durante el transcurso del fin de semana del 14 y 15 de marzo de 2020, pude comprender, a marchas forzadas, que la pestaña de videoconferencias no solo servía como extensión de un centro logístico de transporte de contenidos, sino que podía llegar a simular una clase, dado que fue toda una sorpresa verme en pantalla y oírme. Ello era una posibilidad del equipo portátil, pero no del fijo, cuestión importante, pues el teclado de un equipo fijo suele garantizar mejor la fluidez de la escritura (teclas más separadas y con mayor relieve). Dediqué ese tiempo dominical a familiarizarme con la herramienta.

\section{Situación y escena}

El marco dispuesto para las teleclases fue mi domicilio, en mi cuarto de trabajo habitual. Ha de señalarse que tan solo unos meses antes pude tener instalada la conexión por fibra. Aun así, no soportaba demasiado bien la conexión simultánea, ya que debía dar servicio, además, a tres estudiantes universitarios (dos de ellos de un doble grado) y de una estudiante de $4 .^{\circ}$ curso de Enseñanza Secundaria Obligatoria. Con la adquisición y sencilla instalación de prolongadores de conexión por cable e inalámbricos, el problema quedó totalmente solucionado. Durante el desarrollo de esa actividad, había que procurar que todos los miembros familiares estuviesen avisados para guardar el mayor silencio posible. Siempre se respetó el horario previsto por la facultad de Humanidades de la UAL, de forma, incluso, que el tiempo de clase era estrictamente puntual (en su comienzo y en su final), algo que a mí mismo me sorprendió, con una asistencia aun mayor que en la del aula, circunstancia que no se ha venido repitiendo en lo que llevamos de curso 2020-2021. Creo que un inconveniente pocas veces señalado es la falta de movilidad corporal que supone una teleclase, pues hay que estar siempre relativamente inmovilizado para que sonido e imagen se transmitan bien.

De cualquier modo, es necesario apuntar y recapitular brevemente que esa escena estaba tensada por la conversión de un espacio privado y familiar en un espacio para eventos públicos, lo que no ha servido para acotar mejor en forma de derechos económico-laborales dicha conversión, pero sí en forma de obligaciones, que - por poner un caso - han llegado a prohibir la presencia de terceras personas. La cuestión toma mayores magnitudes, aun, si observamos el aumento de dicha tensión cuando se han celebrado exámenes o se ha pasado a hacer obligatoria la grabación de las sesiones, implicando la confusión entre destinarios y receptores de la información o el controvertido derecho a la protección de datos y a la propiedad intelectual. No obstante, es de interés declarar, al menos, que las consecuencias comunicativas y sociolingüísticas de esa transformación están en general por analizar en sus diferentes

Espiral. Cuadernos del Profesorado | ISSN 1988-7701 | 2021, 14(29), 5-17 
dimensiones. Por razones de espacio, aquí se irán apenas esbozando en el conjunto de componentes del modelo SPEAKING.

\section{Participantes}

El grupo de clase estaba compuesto por 58 estudiantes, de los cuales seis eran de intercambio internacional (cuatro de Irlanda, una de Francia y otra de Alemania; solo la alumna francesa volvió a su país para seguir las clases). El delegado me comunicó, en una videoconferencia celebrada al efecto, que alrededor de un $20 \%$ del grupo tenía poca o nula disponibilidad de dispositivos electrónicos y, sobre todo, problemas de conexión a internet, no solo por la conexión en sí, sino también por la inestabilidad de la aplicación informática del aula virtual, saturada simplemente por el uso de más de tres usuarios con cámara y micrófono, último aspecto que, le comenté yo, subiría el porcentaje al 100\%. En otras palabras, la sintaxis digital estaba amenazada ya de partida. Había 39 mujeres y 19 hombres, que, en general, mostraron un grado de dedicación y motivación bastante menor que en las mujeres. Como se ha dicho anteriormente, el profesor era principiante total en estas tareas de clases online, igual que el grupo de estudiantes. Normalmente, resultó ser un grupo sin tensiones destacables; se produjo un clima de mucha confianza y agradecimiento, pues argumentaban que era la única asignatura que mantenía el ritmo regular de clases, no solo para resolución de dudas. El espacio áulico-virtual no se aprecia en el centro de la pantalla, si bien se actualiza constantemente la lista de estudiantes conectados en ese momento. Ese centro de pantalla actúa como monitor de lo que ocurre desde el punto de vista docente.

\section{Finalidades}

Ya se ha indicado que esta actividad tiene un neto propósito académico: continuar con otros medios lo que es el desarrollo normal de la docencia en un contexto de pandemia, salvando de la mejor manera posible los inconvenientes telemáticos; esto es: lo deficitario era la no presencialidad y se luchaba implícitamente por minimizar sus posibles estragos en esta nueva escena. De ese modo, se generó una tendencia discursiva en forma de metaclases, obligada por el mal funcionamiento de la aplicación, lo que precisaba de muchas repeticiones, no tanto del contenido, sino para explicar más detalladamente el tipo de trabajos encargados y la negociación matizada de los plazos estipulados.

\section{Secuencia de actos}

Desde el punto de vista del profesor, la secuencia comenzaba procurando preparar los archivos necesarios para el desarrollo de la clase. A partir de ese momento, se producía una conexión de prueba, que perseguía también un entrenamiento en estas secuencias de microactos novedosos, similar a cuando estamos aprendiendo las primeras estructuras léxico-sintácticas de otra lengua. No obstante, a pesar de que esa conexión se producía minutos antes, el grupo estaba prácticamente conectado ya en su totalidad, lo que valía también para que me ayudasen a resolver incidencias por la escasa pericia en el manejo de la aplicación. En general, cabe decir que el tedio provocado por la nula interacción con el alumnado era agotador, con la creciente y muy dolorosa sensación de ser un dispositivo encendido ante quienes no ves sus caras ni sus reacciones por el desarrollo de la clase. Con el tiempo pude desarrollar algunas habilidades, más o menos jocosas, para que al menos enviaran algunos testimonios fáticos, es decir, para apuntar que todo estaba bien. Así fue como, poco a poco, aparecía en pantalla esa herramienta disciplinaria (levantar la mano) que proporcionaba mucha alegría, pues si alguien la utilizaba es que estaba siguiendo el hilo de la exposición e iba a intervenir sonoramente. Cuestión aparte merece el desarrollo de las sesiones prácticas (más cortas, de una hora de duración) que, sinceramente, se desarrollaron más fluidamente que siendo presenciales, quizá porque ya habían desarrollado mucha pericia en la interacción escrita (el chat, que reflejaba las intervenciones en la parte lateral derecha) y habían preparado con tiempo sus comentarios. Uno de los aspectos más complejos era la conversión de archivos para su aparición en la pantalla. La secuencia articulatoria era así: COMPARTIR CONTENIDO (en el centro de la parte inferior del lateral derecho) $>$ COMPARTIR ARCHIVOS $\left(4^{a}\right.$ pestaña en orden descendente de la parte lateral derecha). El uso de dicha posibilidad entorpecía bastante las sesiones, pues - para ahorrar tiempo - previamente había de efectuarse la conversión de formato, que duraba varios minutos. A la postre, ya en el primer cuatrimestre del curso 2020-2021, descubrí la posibilidad articulatoria de COMPARTIR PANTALLA > VENTANA DE LA APLICACIÓN (en el 
centro del siguiente menú desplegable). Estas secuencias eran mucho más ágiles, dado que — de forma bastante más sencilla - puede visualizarse en la pantalla de los estudiantes cualquier archivo ya preparado o cualquier otro de inmediata recuperación, también enlaces electrónicos que pudieran completar e ilustrar de forma imprevista las sesiones. Una de las ventajas del aula virtual es la facilidad de la identificación. Al abrir la videoconferencia se conocían cuántos y quiénes eran los participantes de la asignatura. Un simple saludo (que habitualmente provoca la devolución de otro saludo) servía para verificar quiénes estaban atentos y quiénes estaban en otra cosa. Otro aspecto relevante es que, de forma sorprendentemente habitual, se producen muchas incidencias (molestas para el campo visual) que señalan que el estudiante está abandonando la sesión o uniéndose a ella, debido a problemas técnicos por conectividad o por inestabilidad de la aplicación de la videoconferencia.

Mención aparte merecen los problemas para estudiantes y profesor que supone el encargo de tareas mediante ACTIVIDADES. Si mantenemos el campo de origen metafórico de lo lingüístico, ACTIVIDADES es probablemente, junto con EVALUACIÓN, la subaplicación (que yo conozca y que crea que necesito como profesor) que precisaría de mucho más aprendizaje, pues la adquisición es muy costosa sin un profesor o conocedor práctico del aula virtual que guíe adecuadamente la consecución de un nivel de dominio aceptable. Así, encontrarlo necesita de varios pasos articulados consecutivamente: ÁREA DE CONTENIDO> EVALUACIONES (inmediatamente abajo, en la parte central; se despliega; 3. ${ }^{a}$ opción)> ACTIVIDADES, y ahí empieza a florecer la fronda léxica, con términos como RÚBRICA, CALIFICACIÓN DELEGADA, TIPO de ACTIVIDAD (Envío individual vs. Envío en grupo), que, sin aprendizaje explícito, guiado por profesorado experto, puede ser desesperante. Destaca la preminencia semiótica de las FECHAS DE VENCIMIENTO o de cláusulas ciberoracionales como las relativas a la calificación. En este supuesto, creo que es necesario entender que hay una docencia ancha, y no tan restringida a las videoconferencias en tanto clases virtuales. Esos módulos de ACTIVIDADES, una vez adquiridos y aprendidos son tremendamente interactivos, ya que ahorran un trabajo ímprobo y burocrático y, sobre todo, pueden transmitir directamente al alumnado comentarios, observaciones, avisos, notas de interés y calificaciones, sirviendo como elementos muy eficaces de mejora.

\section{Tono (clave) de la interacción}

Este componente, inextirpable de cualquier interacción, resulta determinante para el mayor o menor éxito de una clase. Es tan importante que apenas puede ser aprehendido, por moldeable, negociable, elástico y también flexible. Toda la formalidad (o informalidad) académicas han quedado asumidas, las de cercanía y de distancia, las de respeto y de confianza, bajo un contexto muy emotivo, marcado por la incertidumbre vital de la cuarentena. El tono o la clave suele referirse al tono del evento de habla, forma o actitud con que se trasmite al comunicar. Habitualmente los diferentes tonos se inscriben en un continuo que los localiza en términos de mayor a menor informalidad dada por la confianza y cercanía que se logra en el acto de habla, la presencia de ironía, sarcasmo, socarronería, etc. Así, había muchas más interpelaciones y preguntas recíprocas por la salud, de manera que la denominación de "coronavirus", más habitual en el primer periodo pandémico, era a veces lo no nombrado (junto con sus efectos sociopolíticos), no tanto como una estrategia eufemística, sino estilística ("lo que está pasando ahora"; "ahora"; "la situación"; "el bicho"; "el microbio este", "el encierro"; "el arresto domiciliario", etc.). De ese modo, este registro académico se caracterizó en mucha mayor medida en descubrir al enunciador, con menor foco hacia los datos y los conocimientos. Esto es, se hacía mayor hincapié en estrategias hacia la comunicación y menos hacia la información; con el entrenamiento en el dispositivo telemático se intentaba no tanto eliminar el tono académico, sino arroparlo, saliéndonos con frecuencia de ese circuito más frío, haciendo bromas, con espíritu jocoso como útil contra la nueva enfermedad.

\section{Instrumentos}

Sin duda alguna este componente está siendo el macrosoporte al que deben adaptarse los demás, convirtiéndose en el pegamento interpersonal más determinante en las teleclases. Como parte recién incorporada a las utilidades del aula virtual, el módulo de VIDEOCONFERENCIAS ha hecho posible la continuación de la actividad académica, la que ha reafirmado a las personas en torno a un cierto 
sentimiento de comunidad muy maltratado por los rigores de una cuarentena domiciliaria prolongada. La esencia explicativa de esta enorme influencia se sustancia a partir de la llamada ubiquidad; es decir, que, estando en sitios físicamente distintos, pudiésemos celebrar un evento comunicativo simultáneo y simulado (y/o ampliado) por imagen y sonido mediante herramientas informáticas. Y aquí no se podía —o no se debía - desaconsejar su uso por falta de pericia, como se apuntó en otro trabajo (Fuentes González, 20117). Tampoco debemos olvidar que, como parte de ese repertorio instrumental, las bibliotecas universitarias deben estar interconectadas más que nunca con la docencia y agilizar verdadera y eficazmente la distribución del uso de contenidos digitales, pues, en este ámbito, observo cómo el alumnado mantiene indicadores de confianza más positivos hacia la bibliografía en papel que hacia la digitalizada, a pesar del acceso cómodo y gratuito de muchos materiales, aspectos de los que ya se van tomando nota (Arroyo-Vázquez y Gómez-Hernández, 2020).

Todo ello recuerda nuevamente el aprendizaje-adquisición de una L2 o LE, con los característicos influjos de la interlengua, inestable, transitoria y difícilmente sistematizable; es decir, que el aula y sus procedimientos, en forma de L1 (lo presencial; con una buena dosis de flujo entre competencia y actuación; de fluidez lingüística y de un amplio despliegue de posibilidades sociolingüísticas y comunicativas) son LA forma de dar las clases virtuales. Esa especie de L1 metafórica de lo presencial presiona mucho al principio en las secuencias que se van logrando en L2 (lo no presencial; el aula virtual con sus videoconferencias, con cortes del hilo expositivo, impedancias, interferencias, acoples de sonido, desconexiones, etc.), L2 muy embrionaria debido a la poca exposición a ese recurso, que necesita cierta experiencia en forma de verdadera inmersión lingüística, igual que el número de exposiciones ante el vocabulario, que no se aprende simplemente porque lo memoricemos o porque se escriba en la pizarra, pues una cosa es conocerlo y otra, bien distinta, actualizarlo sin muchos titubeos en sus usos más habituales. Estoy hablando de las clases del primer y desconcertante periodo de confinamiento, pero ese sentimiento de comunidad más o menos cohesionada creo que se ha ido disolviendo debido a la creciente desorientación social tras ya casi un año de pandemia, a lo que debe añadirse que la mayoría ingente de estudiantes, también quien esto escribe, preferimos las clases presenciales, sin ningún tipo de dudas y sin hibridarlas simultáneamente para estudiantes no presenciales.

\section{Normas}

En la propuesta de Hymes (1974), las normas son las reglas y principios que rigen la interacción y la interpretación en el habla. Desde esta perspectiva general, conviene mencionar que habitualmente se trata de la regulación de los turnos de habla, del cómo y del cuándo entrar y salir de una interacción, de la forma en que se pide la palabra, de las fórmulas de cortesía explícita y de las maneras en que se es implícitamente cortés. También de cuándo es lícito hablar y cuándo es necesario guardar silencio o qué procedimientos son usados para mantener la atención e interés del auditorio. Evidentemente, el importante proceso disciplinario mediado por la tecnología, ese cibersometimiento arriba mencionado, supone ahora un punto de partida garante del respeto y del cumplimiento de esas posibles normas (por ejemplo, se activa o no por parte del profesor la posibilidad de tener o no la palabra pinchando en la pestañilla la posibilidad de convertir a una estudiante de participante a moderadora ${ }^{8}$. Sin embargo, el primer eslabón donde la garantía queda mermada remite a la propia aplicación, muy inestable, incapaz en muchas ocasiones de garantizar la intervención de una estudiante; salvo en muy contadas ocasiones. Por el motivo que sea, pero en gran parte por razones técnicas, las intervenciones se escuchaban bien excepcionalmente, y casi nunca acompañada de imagen; era como una lengua sometida a unas normas ideales donde la interacción es secundaria y donde lo nuclear era instaurar la centralidad del discurso oral monogestionado, facilitando eso sí, los discursos interaccionales escritos a través de la posibilidad del chat. De ahí que la fluidez comunicativa quedara muy determinada por razones técnicas que señalaban la dualidad de procedimiento oral frente al escrito, dejando un amplio margen de inseguridad a la primera, al tiempo que era rotundamente segura para lo segundo. Sin embargo, en tanto que eventos

\footnotetext{
${ }^{7}$ Para profundizar en los aspectos más generales del uso de TIC en la enseñanza superior, vid. Campos FernándezFígares, Martos García y Quiles Cabrera (2015) y Quiles Cabrera, Martínez Ezquerro y Palmer Campos (2019). ${ }^{8}$ Par léxico que no parece demasiado afortunado; más sencillamente podía ser oyente y hablante, por ejemplo.
} 
comunicativos, las exposiciones orales deben tener un buen grado de interacción. Es cierto que lo telemático puede amparar el escabullirse, escaquearse o hacerse el longui cuando se recibe una petición de intervención, pero es asimismo incontrovertible que los impedimentos técnicos dificultan o impiden también dichas intervenciones. De forma habitual, yo les digo a los estudiantes, "Animaos, no tengáis miedo escénico...". Como regla general se han gestionado bien muchas normas prototípicas de una exposición, y aún de cualquier interacción académica. Entiendo yo que, debido al clima de mutua confianza, todos han satisfecho el par contractual y contactual saludo-saludo y posterior despedidadespedida con índices muy altos de agradecimiento (Gracias por estar ahí, profesor). Ante otro par contractual (pregunta-respuesta), se ha tenido que usar sobremanera la repregunta, con vacíos comunicativos clamorosos (quizá habría que rellenarlos con una banda sonora de circunstancias...). Cuestión distinta es el género de las tutorías, donde el plan de interacción está mucho más planificado (llevan sus notas previas) y donde las interacciones en ciertas ocasiones han estado descompensadas por el abuso de intervenciones de alguna estudiante, frente a otras, que se quejaban de la amplitud del tiempo de intervención de la compañera. Por lo demás, parece una obviedad testimoniar que el conjunto de destinatarios (auditorio y/o telespectadores) estaba respetuosamente atento, quizá porque nos hemos habituado a identificar respeto normativo con silencio, sin caer demasiado en la cuenta de que, con ocasión de la videoconferencia, el silencio es bastante más ambiguo y polisémico (puede señalar que alguien está, pero sin estar ahí...).

\section{Géneros}

Queda claro que el género o subgénero (sociolingüístico) principal es la clase magistral, junto con las sesiones prácticas en forma de seminarios (docencia estrecha). El género tutorías también fue cultivado, pero en mucha menor medida que durante los periodos de presencialidad permitida. Para tiempos futuros, creo que será necesario abundar en la valoración mucho más explícita de la participación en clases y en el uso de tutorías, pues las consecuencias en la calificación también vinculan grupalmente. El éxito o no para desarrollar una buena clase magistral creo que está en conocer bien al alumnado, o en querer conocerlo, en manejar su saber consabido, en propiciar sus intervenciones, en tener la habilidad para recabar en público sus opiniones y sus dudas. Muchas veces, esos intentos caían en el vacío digital, pues no respondían, presumiblemente por problemas informáticos o también por estar testimonialmente conectados, pero no concentrados en la clase, aspecto confesado por algún estudiante. Por razones de espacio, quiero solo apuntar la importancia de lo que denomino el habla espontánea de los pasillos, muy importante en el engranaje de la docencia, pues apenas en unos pocos minutos permite solventar muchas dudas sencillas, pero transformadas en estas circunstancias en un caudal enorme de mensajes (por aula virtual) y de correos electrónicos que exigen mucha dedicación para contestarlos en tiempo y forma.

\section{Reflexiones finales}

Esta aproximación etnográfica ha hecho patentes algunos aspectos problemáticos surgidos en torno a la enseñanza en remoto, obligada por el contexto sanitario. Pasados los primeros momentos de atonía y del posterior y matizado sentimiento de éxito, convendría cuestionar activamente algunas categorías dicotómicas como la prenskyana 'nativo digital vs. inmigrante digital' o, más recientemente la whiteana 'residentes $v s$. visitante', pues tienden a simplificar sobremanera realidades muy complejas. La digitalización como atributo per se de los jóvenes universitarios no parece funcionar demasiado, pues tampoco parecía funcionar mucho antes, más allá de la dependencia vital cotidiana de dispositivos para que circulen abrumadoramente más y más mensajes a una velocidad inusitada, y por tanto teledirigida hacia los accidentes de tráfico, muy cognoscitivos ahora.

Por otra parte, conviene, asimismo, mantener bienes sociales como el tiempo privado y el tiempo laboral, respetando opciones sociopolíticas como un horario regular y un descanso de las tareas. Ese horario es un triunfo que ordena la gestión de las cosas y que permite actuar y anotar críticamente las incidencias digitales de un modo más adecuado.

En todo este entramado sociolingüístico, es fundamental sentir el lenguaje de forma vital, como una influencia recíproca, facilitando su evolución y mejorando las nomenclaturas y la sintaxis de las 
aplicaciones. Para otros trabajos, podrá ahondarse en esta perspectiva etnográfica, compilando relatos sociolingüísticos sobre el manejo cotidiano de las ciberclases que sirvan para potenciar las no pocas ventajas de las plataformas, sin ignorar sus riesgos. Esta ciberenseñanza de principiantes ante una emergencia debería servir para abolir procedimientos de evaluación tan disciplinarios y discretos como los exámenes y cultivar con mayor decisión una enseñanza más continua, participativa y vivencial.

La incertidumbre y la marejada de la novedad ha dejado en el tintero muchas cuestiones de interés que habrían emergido desde una observación más escrupulosa, concienzuda y programada. En el futuro, con la evolución de esta población ahora online habría que dialogar sinceramente, no tanto para verificar el déficit de estudiantes y de profesorado, sino para cimentar unas aplicaciones lingüística y comunicativamente intercomprensivas y mejor normalizadas, que quieran estar al lado del regalo de la comunicación humana, donde el adjetivo intuitivo o amistoso para las herramientas telemáticas no tenga ese sentido meramente comercial.

La representación de lo real-digital nunca podrá sustituir la presencia directa de lo real-físico. Partiendo de estas dos esferas, ni la enseñanza tradicional es nunca tan tradicional ni la enseñanza digital es tan innovadora. Ahora bien, conviene no escatimar esfuerzos en retroalimentar críticamente estas cibertecnologías que en los exámenes no te dejan ni equivocarte. Discutir colectivamente la competencia docente para el mundo digital debería ser una obligación, como ya han advertido Castañeda, Esteve y Adell (2018), porque, si no la disputamos, abonaremos todavía más el terreno hacia el cibersometimiento donde el lenguaje común será el ciberlenguaje impuesto, obedecido, sin los márgenes y los regalos que constituyen la comunicación cara a cara.

Conflicto de Intereses: El autor declara que no tienen conflicto de intereses.

\section{Referencias}

Abreu, J. L. (2020). Tiempos de Coronavirus: La Educación en Línea como Respuesta a la Crisis. Daena: International Journal of Good Conscience, 15(1), 1-15. Disponible en: http://www.spentamexico.org/v15-n1/A1.15(1)1-15.pdf

Adell Segura, J., Castañeda Quintero, L., Esteve Mon, F. (2018). ¿Hacia la Ubersidad? Conflictos y contradicciones de la universidad digital. RIED. Revista Iberoamericana de Educación a Distancia, 21(2), 51-68. DOI: http://dx.doi.org/10.5944/ried.21.2.20669

Aguaded Gómez, J. I. y Díaz Gómez, M. R. (2009). Presencia virtual de las universidades andaluzas. Revista @ tic, 3, 18-28. Disponible en http://hdl.handle.net/10272/6312

Alves dos Santos Conceição, V. y Meneses Chagas, A. (2018). Repertórios linguísticos e linguagens em uma sociedade conectada. En Porto, C. Alves, A. L. y Fontes Mota, M., eds. (2018). EDUCIBER: Diálogos ubíquos para além da tela e da rede. Aracaju - Sergipe, pp. 77-92. Disponible en https://editoratiradentes.com.br/e-book/educiber1.pdf\#page=77

Arroyo-Vázquez, N. y Gómez-Hernández, J. A. (2020). La biblioteca integrada en la enseñanza universitaria online: situación en España. Profesional de la información, 29(4), e290404. https://doi.org/10.3145/epi.2020.jul.04

Campos Fernández-Fígares, M., Martos García, A. y Quiles Cabrera, M. ${ }^{a}$ C. (2015). El desarrollo de las competencias lectoescritoras en el estudiante: colaboración interuniversitaria, TIC e innovación educativa. En Gonzálvez Vallés, J. E., coord. Nuevas tendencias en innovación educativa superior (pp. 163-178). Madrid: ACCI,

Bruzos Moro, A. (2017). De camareros a profesores” de ELE. La mercantilización del español y de su enseñanza como lengua extranjera. Spanish in Context 14(2), 230-249. DOI: 10.1075/sic.14.2.04mor

Castañeda, L.; Esteve, F. y Adell, J. (2018). ¿Por qué es necesario repensar la competencia docente para el mundo digital? RED. Revista de Educación a Distancia, 56, 6. DOI: http://dx.doi.org/10.6018/red/56/6

Codó, E., Patiño-Santos. A. y Unamuno, V. (2012). Hacer sociolingüística etnográfica en un mundo cambiante. Retos y aportaciones desde la perspectiva hispana. En La sociolingüística con perspectiva etnográfica en el mundo hispano: Nuevos contextos, nuevas aproximaciones, Spanish in Context 9(2), 167-19. https://doi.org/10.1075/sic.9.2.01cod 
Comisión Europea (2017). Marco Común de Competencia Digital Docente. Gobierno de España-MECyD-INTEF. http://educalab.es/documents/10180/12809/marco+competencia+digital+docente+2017/afb07987-1ad64b2d-bdc8-58e9faeeccea

Consejo de Europa (2001/2002). Marco Europeo de Referencia para las lenguas: Aprendizaje, enseñanza, evaluación. Madrid: MECyD.

Duranti, A. ([1997]2000). Antropología Lingüística. Madrid: Cambridge.

Fernández-Gubieda, S., coord. 2020. Aprendizajes de la enseñanza universitaria en tiempos de la COVID-19. Ediciones Universidad de Navarra. Disponible en https://dadun.unav.edu/handle/10171/59097

Freire, J. ed. (2009). Monográfico cultura digital y prácticas creativas en educación. RUSC, Revista de Universidad y Sociedad del Conocimiento, 6(1). http://dx.doi.org/10.7238/rusc.v6i1.23

Fuentes González, Antonio Daniel (2011). Apuntes y reflexiones para una mejora de habilidades lingüísticas y comunicativas en la exposición oral del alumnado universitario. LinRed, 9. http://www.linred.es/informacion_pdf/LR_informacion_30102011.pdf

Gabarrón Pérez, A. (2020). Competencia digital del profesorado no universitario de lenguas extranjeras y su vinculación con las competencias comunicativa y sociolingüística. Revista de Educación de la Universidad de Granada, 27, pp. 73-89. http://doi.org/10.30827/reugra.v27i0.143

Golluscio, L. A., comp. (2002). Etnografía del habla. Textos fundacionales. Buenos Aires: Eudeba.

Guasch, Ó. (1997). Observación participante. Madrid: Centro de Investigaciones Sociológicas.

Guber, R. (2001). La etnografía. Método, campo y reflexividad. Buenos Aires: Norma.

Hine, C. (2000/2004). Etnografía virtual. Barcelona: UOC. Trad. de Cristian P. Hormazábal.

Izquierdo Collado, J. D. (1991). Max Weber: precedentes y claves metodológicas. Cuenca: Universidad de Castilla La Mancha.

Juan Escrihuela, E. (2017). La Sociolingüística de Redes y los Social Media. TRIANGLE. Language, Literature and Computation, Volume 15, pp. 51-101. DOI: 10.17345/triangle15.51-101

Jiménez González, A. y Rendueles Menéndez de Llano, C., coords. (2020). Capitalismo digital. Teknokultura. Revista de Cultura Digital y Movimientos Sociales $17(2)$. https://revistas.ucm.es/index.php/TEKN/issue/view/3637

Jiménez González, A. y Rendueles Menéndez de Llano, C. (2020a). Capitalismo digital: fragilidad social, explotación y solucionismo tecnológico. Teknokultura. Revista de Cultura Digital y Movimientos Sociales 17(2), pp. 95-101. https://dx.doi.org/10.5209/TEKN.70378

Lovón, M. y Cisneros, S. (2020). Repercusiones de las clases virtuales en los estudiantes universitarios en el contexto de la cuarentena por COVID-19: El caso de la PUCP. Propósitos y Representaciones, 8 (SPE3), e588. DOI: http://dx.doi.org/10.20511/pyr2020.v8nSPE3.588

Morant Marco, R. y Martín López, A. (2011). La metáfora bélica durante la crisis sanitaria de la gripe A. CLAC. Círculo de Lingüística Aplicada a la Comunicación, 46, pp. 91-112. https://doi.org/10.5209/rev_CLAC.2011.v46.3

Prado Aragonés, J. (2001). La competencia comunicativa en el entorno tecnológico: desafío para la enseñanza. Comunicar, 17, pp. 21-30. Disponible en: http://www.redalyc.org/articulo.oa?id=15801704

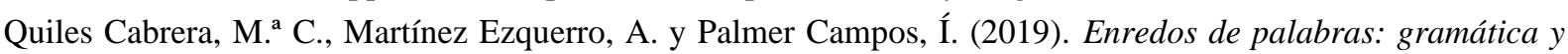
enseñanza de la lengua en nuevos espacios de comunicación. Barcelona: Graó.

Razac, O. (2015). Historia política del alambre de espino. Barcelona: Melusina.

Rendueles, César (2013). Sociofobia. El cambio político en la era de la utopía digital. Madrid: Capitan Swing.

Ruiz Méndez, M. R. y Aguirre Aguilar, G. (2015). Etnografía virtual, un acercamiento al método y a sus aplicaciones. Estudios sobre las Culturas Contemporáneas, vol. XXI, núm. 41, pp. 67-96. https://www.redalyc.org/pdf/316/31639397004.pdf

Santaella, L. (2004). Navegar no ciberespaço: o perfil cognitivo do leitor imersivo. São Paulo: Paulus.

Tejedor, S., Cervi, L., Tusa, F. y Parola, A. (2020). Educación en tiempos de pandemia: reflexiones de alumnos y profesores sobre la enseñanza virtual universitaria en España, Italia y Ecuador. Revista Latina de Comunicación Social, 78, pp. 1-21. https://www.doi.org/10.4185/RLCS-2020-1466

Weber, M. (1904/2009). La “objetividad” del conocimiento en la ciencia social y en la política social. Madrid: Alianza. Edic. de Joaquín Abellán. 